\title{
Seroprevalence of mucosal and cutaneous human papillomavirus (HPV) types among children and adolescents in the general population in Germany
}

Anna Loenenbach ${ }^{1,2^{*}}$, Michael Pawlita ${ }^{3}$, Tim Waterboer ${ }^{3}$, Thomas Harder ${ }^{1}$, Christina Poethko-Müller ${ }^{4}$,

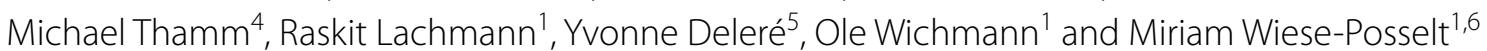

\begin{abstract}
Background: In Germany, HPV vaccination of adolescent girls was introduced in 2007. Nationally representative data on the distribution of vaccine-relevant HPV types in the pre-vaccination era are, however, only available for the adult population. To obtain data in children and adolescents, we assessed the prevalence and determinants of serological response to 16 different HPV types in a representative sample of 12,257 boys and girls aged 1-17 years living in Germany in 2003-2005.
\end{abstract}

Methods: Serum samples were tested for antibodies to nine mucosal and seven cutaneous HPV types. The samples had been collected during the nationally representative German Health Interview and Examination Survey for Children and Adolescents in 2003-2006. We calculated age- and gender-specific HPV seroprevalence. We used multivariable regression models to identify associations between demographic and behavioral characteristics and HPV seropositivity.

Results: We found low but non-zero seroprevalence for the majority of tested HPV types among children and adolescents in Germany. The overall seroprevalence of HPV-16 was 2.6\%, with slightly higher values in adolescents. Seroprevalence of all mucosal types but HPV-6 ranged from 0.6\% for HPV-33, to 6.4\% for HPV-31 and did not differ by gender. We found high overall seroprevalence for HPV-6 with 24.8\%. Cutaneous HPV type seroprevalence ranged from 4.0\% for HPV-38 to 31.7\% for HPV-1. In the majority of cutaneous types, seroprevalence did not differ between boys and girls, but increased sharply with age, (e.g., HPV-1 from 1.5\% in 1-3-years-old to 45.1\% in 10-11-years-old). Associations between behavioral factors and type-specific HPV prevalence were determined to be heterogeneous.

Conclusions: We report the first nationally representative data of naturally acquired HPV antibody reactivity in the pre-HPV-vaccination era among children and adolescents living in Germany. These data can be used as baseline estimates for evaluating the impact of the current HPV vaccination strategy targeting 9-14-years-old boys and girls.

Keywords: Human papillomavirus, Seroprevalence, Risk factors, Children, Adolescents, Germany

*Correspondence: LoenenbachA@rki.de

${ }^{1}$ Department for Infectious Disease Epidemiology, Immunization Unit, Robert Koch-Institute, Berlin, Germany

Full list of author information is available at the end of the article

\section{Background}

Infections with human papillomaviruses (HPVs) are among the most common sexually transmitted infections but can also be transmitted perinatally. HPV belongs to the diverse Papillomaviridae virus family and comprises 
over 200 different types, which can be further categorized based on different parameters [1-3]. HPV types belong to different genera and species based on their phylogenetic relationship [4]. They can also be categorized into two tropism groups, comprising cutaneous HPV types (cutHPV) and mucosal types (mucHPV). Only a small fraction of mucHPV belonging to the alpha genus, like HPV-16 and HPV-18, are assigned to the socalled high-risk (HR) group, due to their role as causative agents of various types of precancerous lesions and cancer $[5,6]$. However, the majority of HPV-infected persons develop no visible signs or symptoms, and infections are usually transient and cleared within 12-24 months [5, 7-9]. Infections with other HPV types can lead to different clinical manifestations. The so-called low-risk (LR) types HPV-6 and HPV-11 can cause external benign genital warts [6]. CutHPV, e.g. HPV-1 or HPV-4, are usually found on healthy skin [10], even though they can also be detected in skin lesions such as benign skin warts [4, 6], and some types have been discussed to be involved in skin carcinogenesis [11].

Children and adolescents before sexual debut can also be affected by HPV infections. Typical disease manifestations of HPV infection in children are skin warts [12], commonly transmitted by cutHPV infections [13]. Skin warts are mainly caused by HPV types 1, 2, 3, 4, 27 and 57 [3]. There are different types of warts, including common warts (verruca vulgaris), plantar warts (myrmecias) and flat warts (verruca plana) with different prevalence and age distributions, which could be due to differences in transmission modes [3, 14]. Generally, HPV associated skin warts are rare in preschool children, and peak among children aged 10-14 years, followed by a rapid decline at 20 years of age with no difference between girls and boys [3]. Other rare diseases caused by HPV infections in children and adolescents are juvenile-onset recurrent respiratory papillomatosis (JoRRP), oral papilloma or anogenital warts [15]. JoRRP is most prevalent among children under five, mainly caused by persistent HPV- 6 and HPV-11 infections and associated with maternal transmission [15]. However, there is also growing evidence of HR-HPV infections in healthy children $[3,16]$.

There are only few HPV serology data in children available, even though research on HPV infections in children already started more than 50 years ago [17-19]. Research primarily focused on modes of HPV transmission such as perinatal mother-infant transmission [16] or prevalence among adolescents related to the start of sexual activities. Study results on risk of vertical transmission vary [20, 21 ] and the exact routes remain unclear [22]. Nevertheless, detection of genital HR-HPV DNA in infants has been repeatedly reported by various studies [21, 23, 24].
Next to perinatal transmission, alternative routes were addressed, such as periconceptual, antenatal, via amniotic fluid [22]. HPV infections can be also horizontally transmitted via autoinoculation, heteroinoculation or via fomites [3, 25, 26]. HPV infections leading to anogenital warts in children are also discussed as a result of sexual transmission in the context of sexual abuse [14, 27]. Anogenital warts, based on vertical or sexual transmission are mainly due to mucHPV 6, 11, 16 und 18 [3, 27]. Anogenital warts due to cutHPV 1, 2, 3 or 4 can be due to heteroor autoinoculation [3]. It is important to notice, however, that the exact transmission routes in infants and children remain controversial $[3,26,28]$, which makes it even more relevant to evaluate age-specific prevalence data in this population.

To investigate the prevalence of HPV infections, DNA testing is used as the reference standard for the detection of current HPV infections [29]. While DNA testing is not an appropriate method to assess previous infections [30], testing for HPV-specific antibodies in an unvaccinated population provides information about past HPV exposure [30, 31]. HPV serology has been established as an important method for population-based studies focusing on type-specific cumulative lifetime exposure to HPV. However, there are only few seroprevalence studies that focus on children [16, 32-34].

Our study aimed to determine age-specific HPV seroprevalence in a representative sample of 12,257 boys and girls aged 1-17 years living in Germany in the years 2003 to 2005. As HPV vaccination of girls has only been introduced in Germany in 2007, our results show naturally acquired antibody reactivity in the pre-HPV vaccination era.

\section{Methods}

\section{Study population}

Archived serum samples were obtained from the German Health Survey for Children and Adolescents (KiGGS) carried out by the Robert Koch Institute (RKI) from 2003 to 2006 [35]. This cross-sectional health survey was the baseline study of the RKI health monitoring program and aimed to collect and analyze nation-wide representative data on the health status of children and adolescents in Germany aged 0-17 years [36]. Recruitment was based on a two-stage stratified cluster sampling design, with participants randomly selected from the population registers of 167 cities in Germany (for a detailed description of the study design, see $[36,37])$. The overall response rate was $66.6 \%$ [36].

The study was conducted according to the Federal and State Commissioners for Data Protection guidelines and was approved by the Charité University Medicine Berlin ethics committee and the Federal Commissioner for Data 
Protection. Informed written consent and agreement were obtained from the parents of all participants.

\section{Survey methods}

In the KiGGS study, a total of 17,641 children and adolescents aged 0-17 years were interviewed and medically examined. Of those, 14,386 participants aged 1-17 years provided a blood sample. As we could not test around $15 \%$ of the sera samples because they were already used up in the core study $(n=14,302)$, or could not be successfully tested in the laboratory for reasons like insufficient bead count $(n=84)$, the overall number of serum samples available for this study were 12,257 (85.2\%).

Standardized self-administered questionnaires were used to obtain information on socio-demographic and lifestyle variables. Questionnaires were filled out by the parents of all children (1-17 years) and by the children themselves ( $>10$ years). Age was categorized into seven groups (1-3, 4-6, 7-9, 10-11, 12-13, 14-15, and 16-17). Region of residence was split into two groups, with 'West Germany' and 'East Germany', considering the former boarders of the German Democratic Republic and the Federal Republic of Germany from 1949 to 1990. Urbanity was categorized as rural ( $<5000$ residents), small city (5000 to $<20,000$ residents), medium-sized city $(20,000$ to $<100,000$ residents) and large city $(\geq 100,000$ residents). The socioeconomic status was based on a parental socioeconomic status (SES) index, including information about education, occupational status, and income of both parents separately. The highest index score was used for the overall household SES. Based on the household SES index, children were categorized into 'low', 'medium' and 'high' SES [38].

\section{Multiplex serology}

In 2016/2017, serum specimens were tested for antibodies to the major capsid (L1) protein of 16 different HPV genotypes at the German Cancer Research Center (DKFZ) in Heidelberg. Serological testing was performed by a glutathione $S$-transferase (GST) capture immunoassay in combination with fluorescent bead technology as previously described [39]. We used the following criteria to select HPV-types for analysis: public health relevance, carcinogenic potential, and associated disease outcomes (Additional file 1: Fig. S1). As little is known about different cutaneous HPV types in children apart from the common cutaneous disease types HPV-1 and HPV-4, we tried to include a broad coverage of phylogenetic genera and species for cutHPV. Finally, nine mucosal (alpha: 6 , $11,16,18,31,33,45,52,58$ ) and seven cutaneous (alpha: 10; beta: 8 , 38, 49; gamma: 4; nu: 41; mu: 1) HPV genotypes were included in the test panel. We measured type-specific HPV seroreactivity in median fluorescence intensity (MFI) units.

For calculating seropositivity, MFI values were dichotomized as positive or negative based on previously established type-specific cutoff-values. Seropositivity was defined as the proportion (\%) of positive tested sera. The cut-off values were established with sera of a cohort of 125 young Korean women who were HPV DNA negative and self-reported to never have had sexual intercourse [40]. The following MFI cutoffs were used for mucHPV: HPV-6: 571, HPV-11: 500, HPV-16: 200, HPV-18: 200, HPV-31: 712, HPV-33: 515, HPV-45: 368, HPV-52: 371, HPV-58: 200. A cutoff of 200 MFI was used for all cutHPV [41].

\section{Statistical analysis}

To assure representativeness of the data at the national level, survey weights were calculated and applied to all estimates, adopting the study sample (providing HPV antibody test results) to the population structure of Germany in 2003 in terms of age, gender, state, size of municipality, education and German/non-German nationality and the regional distribution between East and West Germany. These survey weights, which accounted for the stratified and clustered sample design of the survey, were applied throughout the statistical analyses.

Weighted seroprevalence was calculated for all 16 types separately and for the following groups of HPV types: types included in the bivalent vaccine (HPV-2val, 16, 18), types included in the quadrivalent vaccine (HPV-4val, $6,11,16,18)$, and types included in the nonavalent vaccine (HPV-9val, 6, 11, 16, 18, 31, 33, 45, 52, 58). Groupspecific seroprevalence was calculated as the weighted proportion of participants seropositive to at least one of the HPV-types included in one group. Additionally, MFI were plotted against the percentile for each HPV type individually stratified by gender and age for analyzing antibody reactions without relying on a specific cutoff.

Differences regarding demographic and behavioral characteristic of participants stratified by gender were evaluated by using $\mathrm{chi}^{2}$ or Fishers Exact test. $\mathrm{Chi}^{2}$-tests were used to test for statistical significance in categorical variables $(\mathrm{p}<0.05)$ and logit transformation was applied to calculate confidence intervals $(95 \% \mathrm{CI})$.

We calculated prevalence ratios (PRs) using Poisson regression models to identify factors independently associated with HPV seropositivity for HPV-6, HPV-11, HPV-16, HPV-18 and for at least one of the cutaneous HPV types (HPV-1, HPV-4, HPV-8, HPV-10, HPV-38, HPV-41, or HPV-49) tested for in our analysis (HPVcut). We used PR instead of Odds Ratios to obtain more interpretable association estimates [42]. The modelling was performed using generalized linear models with 
Poisson family with log link function. Additionally, we included the survey design for estimating variance and 95\% CIs. Possible interactions between factors were taken into consideration in the multivariable model. In the final multivariable model, we included all factors that were associated with type-specific seropositivity at a $\mathrm{p}<0.05$ level in a backward step approach. Pearson's correlation coefficient was calculated to identify correlations between HPV types, with attributing small correlation for values between 0.1 and 0.3 , moderate correlation for values between 0.3 and 0.5 for strong correlation for values 0.5 .

Data management and statistical analysis were conducted using Stata, Version 14 (STATA Corp., College Station, TX, US). Percentile plots were created with R Studio, Version R version 3.6.0 (2019-04-26).

\section{Results}

Overall, 12,257 serum samples of children and adolescents aged 1-17 years with valid HPV serology from the pre-HPV-vaccination era were included in the analysis (Fig. 1). Among the participants, $48.7 \%$ were girls $(n=5973)$ and $51.3 \%$ were boys $(n=6284)$. The sociodemographic characteristics of the study population are shown in Table 1.

\section{Seroprevalence mucosal HPV types}

Seroprevalence data and MFI distributions of mucHPV are presented in Fig. 2, and Additional file 2: Fig. S2, Additional file 5: Table S1. Seroprevalence of all but HPV-6 ranged from $0.6 \%$ (95\% CI $0.4-0.8 \%$ ) for HPV33 , to $6.4 \%$ (95\% CI 5.8-7.1\%) for HPV-31. Type-specific HPV seroprevalence did not differ by gender for most mucHPV, except of HPV-6.

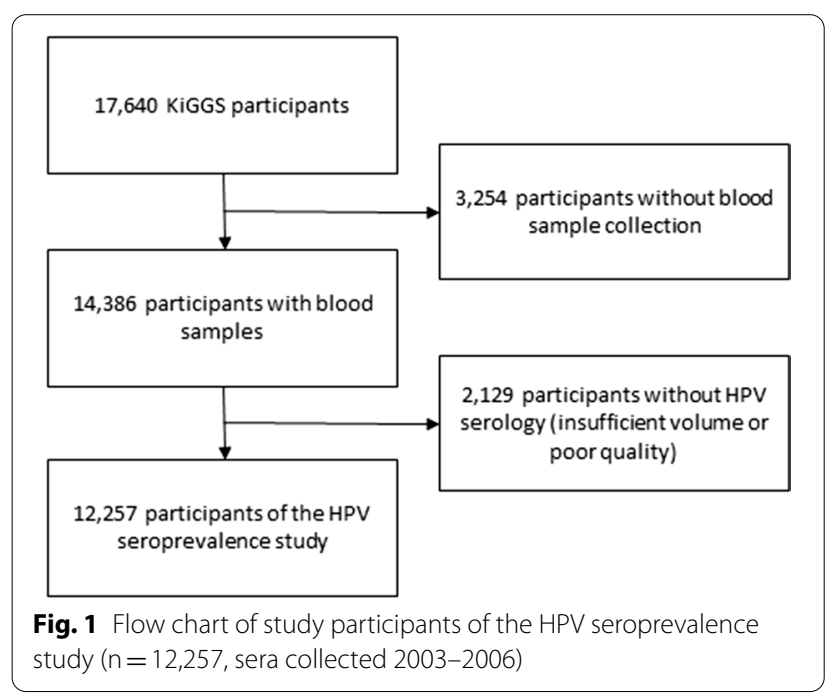

HPV-6 differed to the other mucHPV with a high overall seroprevalence of $24.8 \%$ (95\% CI 23.6-26.1\%). The highest value $(33.8 \%$, 95\% CI 31.0-36.7\%) was observed in the age group 4-6 years. HPV-6 seroprevalence decreased thereafter to $16.6 \%$ (95\% CI 14.5-19.1\%) in the age group 16-17 years. HPV-6 was the only mucHPV which differed by gender with an overall seroprevalence of $23.1 \%$ (95\% CI $21.5-24.7 \%$ ) in girls and $26.4 \%$ (95\% CI $24.9-28.0 \%)$ in boys $(\mathrm{p}<0.001)$. HPV-11 resembled HPV-6 regarding age distribution with highest seroprevalence in the age group 4-6 years.

The overall seroprevalence of HPV-16 was 2.6\% (95\% CI 2.2-3.0\%). It remained relatively stable in the youngest age groups with $1.5 \%$ (95\% CI $0.9-2.6 \%)$ among the 1-3 years-old and $2.1 \%$ (95\% CI $1.4-3.1 \%$ ) among the 12-13 years-old and increased thereafter to $3.1 \%(95 \%$ CI $2.2-4.2 \%$ ) and $4.4 \%$ (95\% CI 3.4-5.8\%) among the age groups $14-15$ and $16-17$ years, respectively.

HPV-18 seroprevalence had a low variability across age groups, with highest seroprevalence in the oldest group (5.1\%, 95\% CI 4.0-6.4\%). Overall, lowest seroprevalence was found for HPV types $33,45,52$, and 58 , with slightly higher values in older age groups. HPV-31 showed the highest seroprevalence $(15.1 \%, 95 \%$ CI 12.6-17.9\%) in the youngest age group, strongly decreasing at higher age.

\section{Seroprevalence of vaccine relevant HPV types}

Overall, 6.1\% (95\% CI 5.5-6.8\%) of the participants were seropositive for at least one of HPV-16 or HPV-18, both types targeted by the bivalent vaccine (HPV-2val) (data not shown). 28.9\% (95\% CI 27.5-30.4\%) were seropositive for at least one of the types covered by the quadrivalent vaccine (HPV-4 val) and around a third (34.0\%, 95\% CI 32.5-35.6\%) were seropositive for one of the nonavalent vaccine types (HPV-9val).

\section{Seroprevalence of cutaneous HPV types}

Seroprevalence data and MFI distributions of cutHPV are presented in Fig. 3, Additional file 3: Fig. S3 and Additional file 6: Table S2. CutHPV seroprevalence ranged from $4.0 \%$ (95\% CI $3.5-4.6 \%$ ) in girls and $4.0 \%$ (95\% CI $3.5-4.5 \%$ ) in boys for HPV-38 to $33.8 \%$ (95\% CI $32.2-$ $35.5 \%)$ in girls and $29.7 \%$ (95\% CI 28.4-31.1\%) in boys for HPV-1 (Additional file 6: Table S2). In most cutHPV, HPV seroprevalence did not differ between boys and girls, except of HPV-1 with 33.8\% (95\% CI 32.2-35.5\%; girls) and $29.7 \%$ (95\% CI 28.4-31.1\% boys) ( $<<0.001)$.

CutHPV seroprevalence increased nearly steadily from youngest to oldest age groups. We found the strongest increase in $\mathrm{HPV}-1$ seroprevalence, ranging from $2.1 \%$ (95\% CI 1.1-4.0\%) in 1-3-years-old to $55.7 \%$ (95\% CI 51.7-59.6\%) in 16-17-years-old among girls 
Table 1 Demographic characteristics of the study participants stratified by gender, HPV seroprevalence study $(n=12,257$, sera collected 2003-2006)

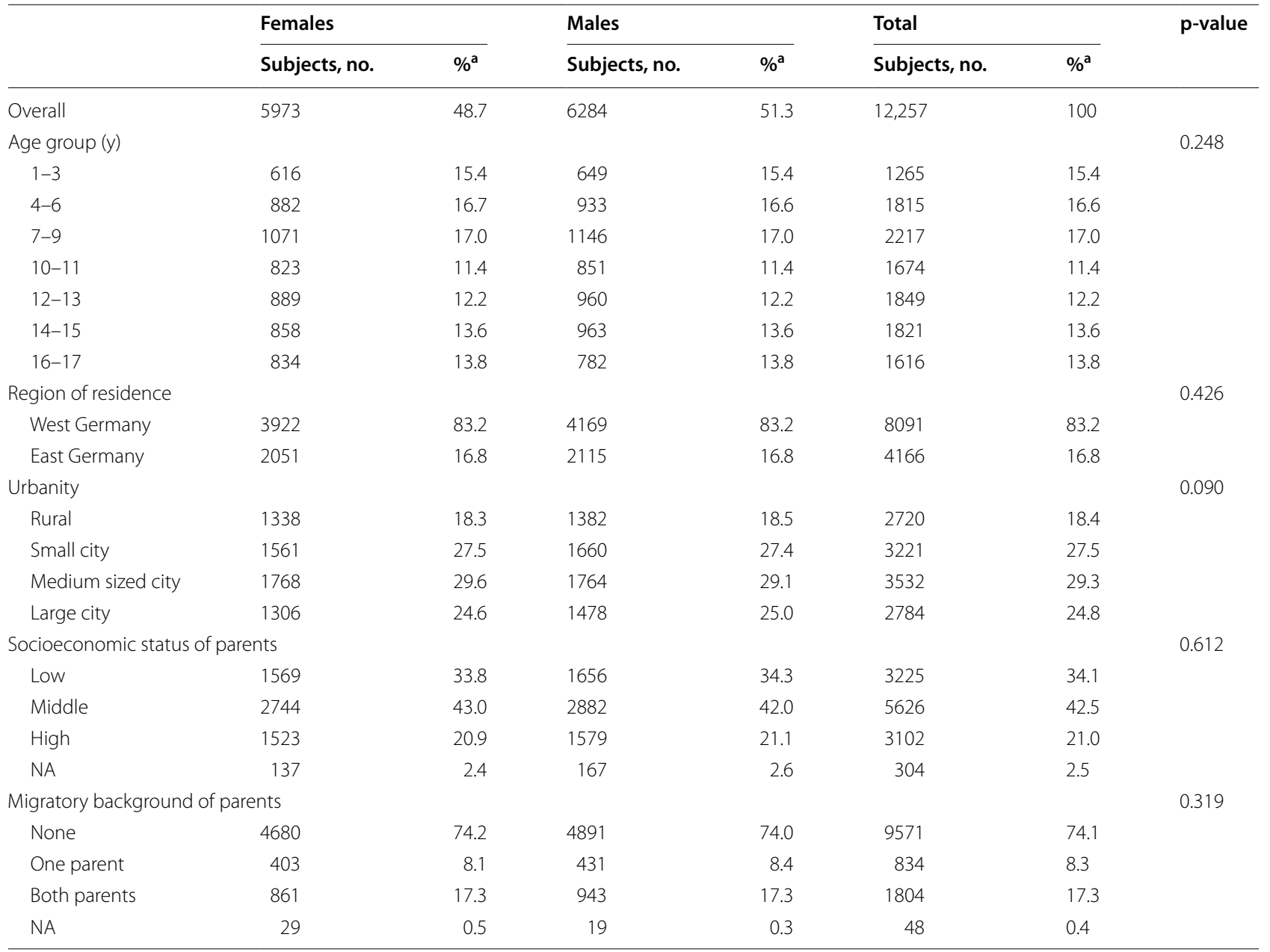

NA not available

${ }^{\text {a }}$ Weighted proportion

\# $\mathrm{p}$-value for difference by gender

and from $0.9 \%$ (95\% CI $0.4-1.8 \%)$ in 1-3-years-old to $47.7 \%$ (95\% CI $43.4-52.0 \%$ ) in 16-17-years-old among boys.

Taken all seven tested cutaneous HPV types together, $46.0 \%$ (95\% CI $44.7-47.3 \%$ ) of the participants were seropositive for at least one HPV-cut type (data not shown). Seroprevalence for HPV-cut increased sharply from $16.0 \%$ (95\% CI $13.5-18.9 \%)$ in the age group $1-3$ years to $57.5 \%$ (95\% CI 54.4-60.6\%) among children aged 10-11 years. Thereafter, seroprevalence for HPV-cut remained relatively stable and increased only slightly to $66.9 \%$ (95\% CI $64.2-69.5 \%$ ) in age group 16-17. No seroprevalence difference was observed between females and males in overall HPV-cut $(\mathrm{p}=0.087)$.
Seroprevalence of single or multiple HPV types $36.6 \%$ (95\% CI $35.1-38.2 \%$ ) of the study population was seronegative for all 16 investigated HPV types. Around a third $(32.7 \%, 95 \%$ CI 31.5-34.0\%) were seropositive for one HPV type, and 16.8\% (95\% CI 15.8-17.7\%) were seropositive for two HPV types. 7.4\% (95\% CI 6.7-8.2\%) of the study population were seropositive for three HPV types, and 6.5\% (95\% CI 5.9-7.1\%) were seropositive for more than three HPV types. In general, multiple HPV seropositivity was influenced by the high proportion of HPV-6 seropositivity. No gender difference was observed for multiple HPV seropositivity $(\mathrm{p}=0.475)$.

The percentage of children being seronegative to any HPV types decreased from $57.2 \%$ (95\% CI 53.1-61.1\%) among 1-3-years-old to $28.8 \%$ (95\% CI 26.1-31.6\%) among 10-11-years-old children and decreased only 


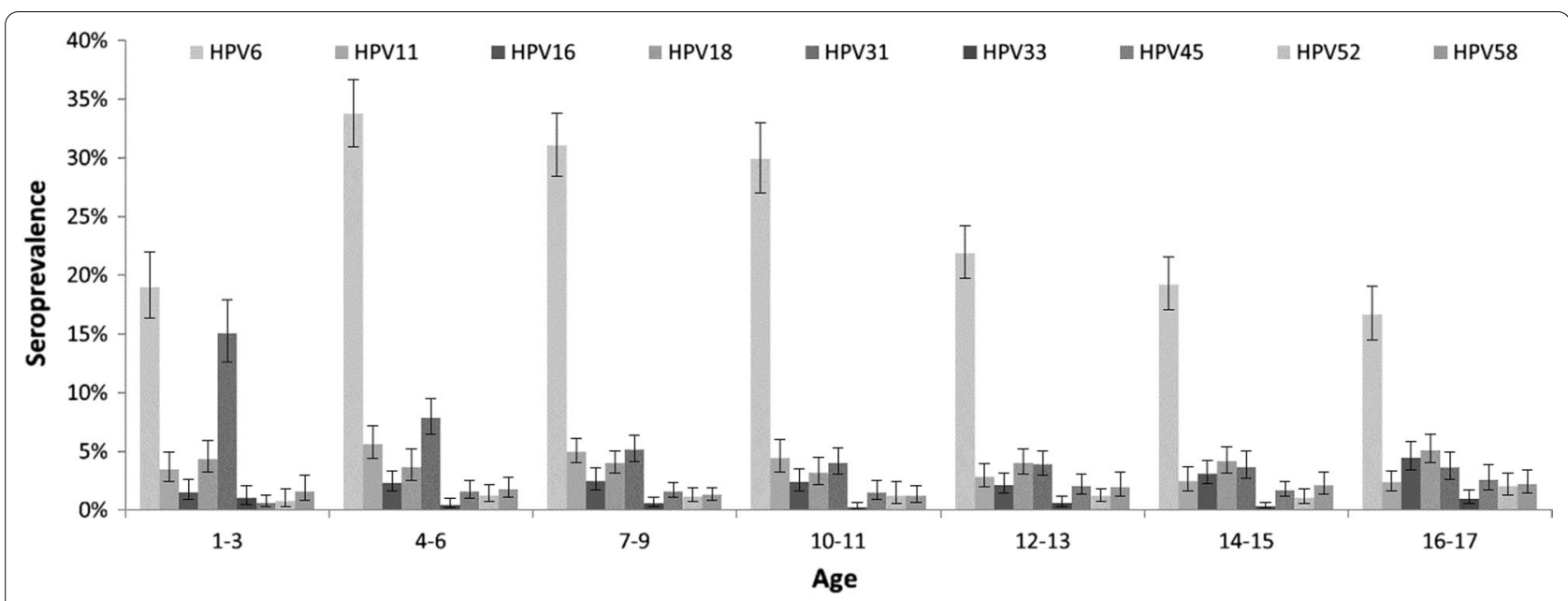

Fig. 2 Seroprevalence of mucosal human papillomavirus types by age, HPV seroprevalence study $(n=12,257$, sera collected 2003-2006)

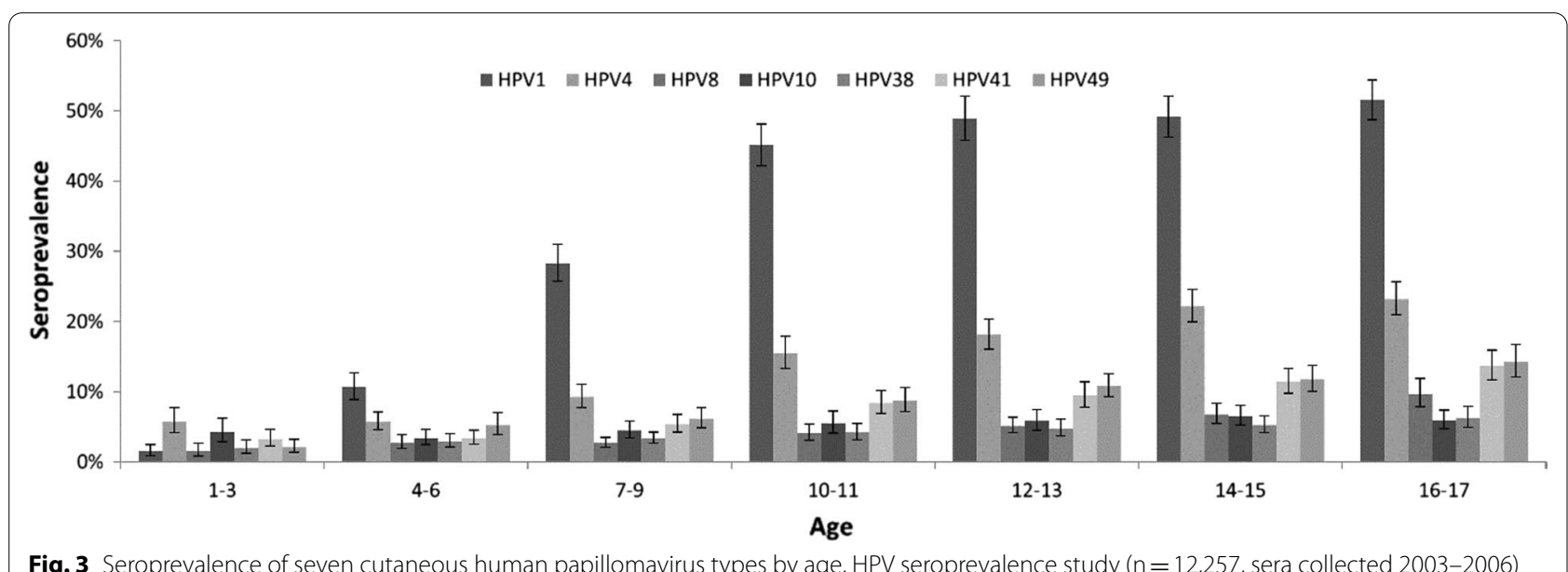

slightly thereafter to $25.7 \%$ (95\% CI $23.3-28.3 \%$ ) among the oldest age group (16-17 years) (Additional file 4: Fig. S4). Accordingly, seropositivity for three or more HPV types increased from $4.7 \%$ (95\% CI 3.6-6.2\%) with 3 types and $1.6 \%$ (95\% CI $0.9-2.8 \%)$ with $>3$ types among the youngest to $9.6 \%$ (95\% CI 8.1-11.3\%) with 3 types and $12.4 \%$ (95\% CI 10.3-14.7\%) with $>3$ types among the oldest age group.

Strong correlation of MFI values was observed among HPV $\alpha 10$ genotypes 6 and $11(r=0.85)$ and HPV $\alpha 9$ types 52 and $58(\mathrm{r}=0.75)$. Moderate correlation was observed among $\alpha 7$ types 18 and $45(\mathrm{r}=0.46)$ and among $\alpha 9$ types, with HPV types $31 / 33(r=0.39), 33 / 52$ $(r=0.49)$, and $33 / 58(r=0.49)$.

Regarding cutHPV, moderate correlation was found only between HPV types 8 and $38(r=0.44), 8$ and 49 $(\mathrm{r}=0.47)$, and 38 and $49(\mathrm{r}=0.43)$.

\section{Factors associated with type-specific seropositivity}

We analyzed possible associations of demographic variables with type-specific seropositivity. The weighted crude and adjusted PR for HPV-16 and HPV-cut can be found in Tables 2 and 3, respectively. Results of the regression analysis for HPV-6, HPV-11, and HPV-18 seropositivity are presented in Additional file 7: Table S3, Additional file 8: Table S4 and Additional file 9: Table S5.

In the fully adjusted HPV-16 model, only age and region of residence were significantly associated with seropositivity. Children of older age (PR 14-15 years: 2.1, 95\% CI 1.2-3.7; 16-17 years: 3.0, 95\% CI 1.6-5.6) and children living in West Germany (PR: 0.7, 95\% CI 0.5-1.0) were more likely to be seropositive compared to younger age groups and to those living in the eastern part of Germany.

While several associations, like number of household members, or number of sunburns, were significant in 
Table 2 Factors associated with seropositivity for HPV-16, HPV seroprevalence study ( $n=12,257$, sera collected 2003-2006) (results from regression analysis)

\begin{tabular}{|c|c|c|c|c|}
\hline & Crude PR $(95 \% \mathrm{Cl})$ & p-value & $\begin{array}{l}\text { Fully adjusted PR (95\% } \\
\text { Cl) }\end{array}$ & p-value \\
\hline Gender & & & $n s^{b}$ & \\
\hline Female & Ref & & & \\
\hline Male & $1.1(0.8-1.4)$ & 0.706 & & \\
\hline \multicolumn{5}{|l|}{ Age group (years) } \\
\hline $1-3$ & Ref & & Ref & \\
\hline $4-6$ & $1.5(0.8-3.0)$ & 0.196 & $1.5(0.8-3.0)$ & 0.198 \\
\hline $7-9$ & $1.6(0.8-3.3)$ & 0.158 & $1.6(0.8-3.2)$ & 0.167 \\
\hline $10-11$ & $1.6(0.8-3.2)$ & 0.184 & $1.6(0.8-3.1)$ & 0.195 \\
\hline $12-13$ & $1.4(0.7-2.8)$ & 0.331 & $1.4(0.7-2.8)$ & 0.348 \\
\hline $14-15$ & $2.0(1.1-3.7)$ & 0.018 & $2.1(1.2-3.7)$ & 0.015 \\
\hline $16-17$ & $3.0(1.6-5.5)$ & 0.001 & $3.0(1.6-5.6)$ & 0.001 \\
\hline \multicolumn{5}{|l|}{ Region of residence } \\
\hline West Germany & Ref & & Ref & \\
\hline East Germany & $0.7(0.5-1.0)$ & 0.055 & $0.7(0.5-1.0)$ & 0.025 \\
\hline Urbanity & & & $n s^{b}$ & \\
\hline Rural & Ref & & & \\
\hline Small city & $0.8(0.6-1.3)$ & 0.423 & & \\
\hline Medium sized city & $0.9(0.6-1.3)$ & 0.499 & & \\
\hline Large city & $0.8(0.5-1.3)$ & 0.370 & & \\
\hline Socioeconomic status of parents & & & $n s^{b}$ & \\
\hline Low & Ref & & & \\
\hline Middle & $0.8(0.6-1.1)$ & 0.132 & & \\
\hline High & $0.8(0.5-1.1)$ & 0.134 & & \\
\hline Migratory background of parents & & & $n s^{b}$ & \\
\hline None & Ref & & & \\
\hline One parent & $0.9(0.5-1.5)$ & 0.596 & & \\
\hline Both parents & $1.3(1.0-1.9)$ & 0.077 & & \\
\hline Number of household members & $1.0(0.9-1.1)$ & 0.752 & $n s^{b}$ & \\
\hline Number of siblings in household & $0.9(0.8-1.1)$ & 0.225 & & \\
\hline Body Mass Index (BMI) & $1.0(1.0-1.1)$ & $<0.001$ & $n s^{b}$ & \\
\hline
\end{tabular}

$P R$ prevalence ratio, $\mathrm{Cl}$ confidence interval, Ref reference

${ }^{a}$ Mutually adjusted for all other variables in the model

${ }^{\mathrm{b}} \mathrm{ns}=$ variables were not significantly associated with HPV seroprevalence in the final model and therefore excluded

the univariable HPV-cut model, a significant association with HPV-cut seropositivity was only observed for age, region of residence, urbanity, and migratory background of parents in the multivariable model. The strongest association with HPV seropositivity for cutHPV was seen for age, with a PR increase from 1.6 (95\% CI 1.3-1.9) among the youngest age groups to 4.2 (95\% CI 3.5-5.0) among the oldest. Living in East Germany, compared to West Germany, was associated with a slightly lower seropositivity $(0.9,95 \%$ CI $0.9-$ $1.0)$. The same was true for living in medium $(0.9,95 \%$ CI $0.9-1.0)$ or large cities $(0.9,95 \%$ CI $0.9-1.0)$, compared to living in rural areas, as well as for migratory background of parents $(0.9,95 \%$ CI $0.8-0.9)$, compared to non-migratory background.

Region of residence was the only variable which was significantly associated with HPV seropositivity in all five regression models. Children living in West Germany were more likely to be seropositive for HPV-6, HPV-11, HPV-16, HPV-18, and HPV-cut, compared to children living in East Germany. HPV-6 and HPV-11 were the only serotypes for which number of siblings (HPV-6: 1.1, 95\% CI 1.1-1.1) or number of household members (HPV-11: $1.1,95 \%$ CI 1.0-1.2) were significantly associated with a slightly higher seropositivity (Additional file 7: Table S3, Additional file 8: Table S4). 
Table 3 Factors associated with seropositivity for HPV-cut, HPV seroprevalence study $(n=12,257$, sera collected 2003-2006) (results from regression analysis)

\begin{tabular}{|c|c|c|c|c|}
\hline & Crude PR $(95 \% \mathrm{Cl})$ & p-value & Fully adjusted PR $(95 \% \mathrm{Cl})^{\mathrm{a}}$ & p-value \\
\hline Gender & & & $n s^{b}$ & \\
\hline Female & Ref & & & \\
\hline Male & $1.0(0.9-1.0)$ & 0.086 & & \\
\hline \multicolumn{5}{|l|}{ Age group (y) } \\
\hline $1-3$ & Ref & & Ref & \\
\hline $4-6$ & $1.6(1.3-1.9)$ & $<0.001$ & $1.6(1.3-1.9)$ & $<0.001$ \\
\hline $7-9$ & $2.6(2.2-3.1)$ & $<0.001$ & $2.6(2.2-3.1)$ & $<0.001$ \\
\hline $10-11$ & $3.6(3.0-4.3)$ & $<0.001$ & $3.6(3.0-4.3)$ & $<0.001$ \\
\hline $12-13$ & $4.0(3.3-4.7)$ & $<0.001$ & $3.9(3.3-4.7)$ & $<0.001$ \\
\hline $14-15$ & $4.0(3.4-4.7)$ & $<0.001$ & $4.0(3.4-4.7)$ & $<0.001$ \\
\hline $16-17$ & $4.2(3.5-5.0)$ & $<0.001$ & $4.2(3.5-5.0)$ & $<0.001$ \\
\hline \multicolumn{5}{|l|}{ Region of residence } \\
\hline West & Ref & & Ref & \\
\hline East & $1.0(0.9-1.0)$ & 0.084 & $0.9(0.9-1.0)$ & $<0.001$ \\
\hline \multicolumn{5}{|l|}{ Urbanity } \\
\hline Rural & Ref & & Ref & \\
\hline Small city & $1.0(0.9-1.0)$ & 0.433 & $1.0(0.9-1.0)$ & 0.447 \\
\hline Medium sized city & $0.9(0.8-1.0)$ & 0.006 & $0.9(0.9-1.0)$ & 0.042 \\
\hline Large city & $0.9(0.8-0.9)$ & 0.001 & $0.9(0.9-1.0)$ & 0.045 \\
\hline Socioeconomic status of parents & & & $n s^{b}$ & \\
\hline Low & Ref & & & \\
\hline Middle & $1.0(1.0-1.1)$ & 0.211 & & \\
\hline High & $1.0(0.9-1.0)$ & 0.329 & & \\
\hline \multicolumn{5}{|l|}{ Migratory background of parents } \\
\hline None & Ref & & Ref & \\
\hline One parent & $0.9(0.8-1.0)$ & 0.018 & $1.0(0.9-1.1)$ & 0.896 \\
\hline Both parents & $0.9(0.8-0.9)$ & $<0.001$ & $0.9(0.8-0.9)$ & 0.001 \\
\hline Number of household members & $1.0(1.0-1.1)$ & 0.003 & $n s^{b}$ & \\
\hline Number of siblings in household & $1.0(1.0-1.1)$ & $<0.001$ & $n s^{b}$ & \\
\hline $\mathrm{BMI}$ & $1.1(1.0-1.1)$ & $<0.001$ & $n s^{b}$ & \\
\hline Breastfeeding & & & $n s^{b}$ & \\
\hline Never & Ref & & & \\
\hline Yes (but not solely) & $1.0(1.0-1.1)$ & 0.345 & & \\
\hline Yes, full till 4th month & $0.9(0.9-1.0)$ & 0.033 & & \\
\hline Yes, full till 6th month & $0.8(0.8-0.9)$ & $<0.001$ & & \\
\hline Sunburn & & & $n s^{b}$ & \\
\hline No & Ref & & & \\
\hline Yes, several times & $1.4(1.2-1.5)$ & $<0.001$ & & \\
\hline Yes, one time & $1.4(1.3-1.4)$ & $<0.001$ & & \\
\hline Don't know & $1.3(1.2-1.5)$ & $<0.001$ & & \\
\hline
\end{tabular}

$P R$ prevalence ratio, $\mathrm{Cl}$ confidence interval, Ref reference

${ }^{\text {a }}$ Mutually adjusted for all other variables in the model

${ }^{\mathrm{b}} \mathrm{ns}=$ variables were not significantly associated with HPV seroprevalence in the final model and therefore excluded

\section{Discussion}

Data on HPV infections from the pre-vaccination era are crucial to evaluate the impact of HPV vaccination. Although not all HPV infections lead to seroconversion, population-based seroprevalence studies are suitable to inform about prior cumulative exposure to HPV in different age groups. While most of the serological studies focus on adult population or adolescents, data on 
type-specific antibody reactivity in children and adolescents of all ages and both genders are scarce. We examined nationally representative data on children and adolescents aged 1-17 years to determine seroprevalence of nine mucosal and seven cutaneous HPV serotypes in 2003 to 2006, before the introduction of HPV vaccines in Germany.

HPV seroprevalence of mucHPV was generally low among children and adolescents. Type-specific seroprevalence was $<3 \%$ for HPV-16, 33, 45, 52, and 58, around $4 \%$ for HPV-18 and 11 , and around $6 \%$ for HPV- 31 . HPV-6 showed relatively high antibody reactivity with around a quarter of the children and adolescents being seropositive. We observed considerable seroprevalences of several mucHPV in children who were above the age of having maternal antibodies gained through a potential vertical transmission and under the age of being sexually active and having gained HPV antibodies through sexual contact. However, most of the children showed low typespecific mucosal antibody titers, compared to cutHPV. Seroprevalence of cutHPV were generally higher, with most HPV types ranging between 4 and $8 \%$, as well as $14 \%$ and $32 \%$ for HPV- 4 and HPV-1, respectively. High reactivity in cutHPV was especially evident for HPV-1, which was present in around $50 \%$ of the children above the age of 10 years.

While many international studies have investigated HPV serology in adults, only few serological studies targeted children and adolescents [33, 43-50]. However, most of them are limited by small sample size $[41,49,51$, 52], focus on single or highly selected mucHPV [32, 44, 47], or target specific age groups [50, 53]. Most serological studies do not analyze age-specific seroprevalence of children under the age of 10 (mainly because of small sample size) [41, 43, 45, 51, 52, 54-56], or include only females $[45,57,58]$.

The focus on HPV prevalence among infants or adolescents is usually based on different theories and approaches of HPV transmission in children and adolescents. Mainly older studies focused on exploring seroprevalence based on vertical (mainly perinatal) transmission, reporting varying risk of transmission between 4 and $22 \%$. Maternal transmission was addressed by several research papers [16, 20,21, 27, 59], showing that about $30 \%$ of HPV positive children share at least one (cutaneous) HPV type with their mother (or also father) [3]. Although perinatally acquired HPV infections may persist up to 3 years $[24,60,61]$, it was concluded that the overall risk of vertical HPV transmission is relatively low [62].

Others have analyzed the age-dependent increase of mucosal HPV seroprevalence in older children and adolescents which was assumed to reflect sexual transmission of HPV due to onset of sexual activity. However, mucosal HPV prevalence was also detected in children of other age groups, irrespective of sexual transmission $[16,18]$. Subsequently, it has been increasingly described that mucosal antibody reactions (or HPV DNA detection) in children should not be automatically seen as a reliable marker of sexual abuse and alternative transmission routes of HPV should be considered [3, 20, 27, 56, 63, 64]. Non-sexual and non-vertical HPV infections in children have been described as potentially horizontally transmitted [20], by self- or heteroinoculation (e.g. anogenital to hands or finger to mouth) $[3,16,65]$. This is supported by Syrjanen [63], who describes that typical anogenital HPV types, like HPV 6, 11, or 16, are also commonly found in oral mucosa $[66,67]$. The horizontal transmissions may explain the seroprevalence of mucHPV among children in our study. Another explanation is that early acquired infections through vertical transmissions can lead to latent infections in children, which may remain for several years $[63,68]$.

Type-specific HPV seroprevalence in children showed a considerable variability in previous studies. HPV16 seroprevalence ranged from $0.0 \%$ in a study with 128 children aged 0-9 years in Australia [43] to 10.9\% in a study with 46 children aged 2-7 years in South Africa [69]. In a study including 257 male students aged 9-14 years from Mexico City, HPV 16 seroprevalence was $6.2 \%$ [70]. A study from Germany including 187 children aged 1-14 years measured a seroprevalence of $0.5 \%$ [41]. However, age groups within studies differed substantially and numbers of participants (under the age of 18 years) were small in all studies. A study by Dunne et al. [55], including higher numbers of children, reported an HPV-16 seroprevalence of $2.4 \%$ among 1,316 children aged 6-11 years in the United States. They found a seroprevalence of $0.4 \%$ among 429 children aged $6-7$ and $3.3 \%$ among children aged $8-11$ years. A study by Cubie and colleagues reported an HPV-16 seroprevalence of $7.6 \%$ among 1192 schoolgirls aged 11-13 years, which is higher compared the HPV-16 seroprevalence of $2.7 \%$ and $2.1 \%$ among girls aged $10-11$ and $12-13$ years found in our study [50]. A study from Sweden including 1031 children aged $0-13$ years calculated an HPV-16 seroprevalence of $3.0 \%$ [32], which is comparable to the overall HPV-16 seroprevalence of $2.6 \%$ in our study population.

In the same study, HPV-16-seroprevalence was highest $(5.2 \%)$ among infants aged $0-0.5$ years and again high with $6.1 \%$ and $3.2 \%$ among children aged $7-10(n=165)$ and $10-13$ years of age $(n=124)$ [32]. A bimodal age distribution has been discussed before [18] and was also reported for asymptomatic HPV infections of the oral mucosa, with a first peak prior to 1 year of age and a second peak in adolescence [3]. In our data, HPV-16 
seroprevalence remained relatively stable between 1.5 and $2.5 \%$ among children under the age of 14 years and increased slightly to $4.4 \%$ in the oldest age group, following a rather typical age distribution based on an increased exposure due to sexual transmission of HPV16 as reported by others $[45,56,57,71]$. However, it is important to notice, that we could not include infants under the age of 1 year.

An age distribution similar to that of HPV-16 seroprevalence was observed for HPV-18, HPV-45, HPV-52 and HPV-58. The opposite was true for HPV-6, HPV-11, and HPV-31: the highest seroprevalence was observed in younger age groups, followed by lowest HPV seroprevalence in the oldest age groups. This is not in line with results from another study, even though a comparison is limited as younger age groups are combined broadly and numbers are low within those age groups in the study from Australia [43]. However, a bimodal age distribution with high numbers of HPV infections (e.g. HPV-6) among the youngest age groups were also found by DNA testing [72]. Compared to most mucHPV, we observed higher seroprevalence of cutHPV, especially for HPV-1, which is in line with other reports $[41,50]$.

Using HPV-specific antibodies as a measure of previous infections poses several challenges. While it has been shown that mucosal HPV antibodies can serve as an indicator of previous HPV infections [73], varying seroconversion rates [74] and latency time of antibody development limit their value. In females, following natural infections with HPV, antibody responses are only detectable in about $50-70 \%$ of cases [74, 75], with the majority of responses being weak. A study by Antonsson et al. [76] showed that there was little difference in HPV antibody stability between men and women. Another limitation of serological HPV studies is the question of antibody stability over time. Whereas antibody titers have been shown to be relatively stable for mucosal types [73], the stability of cutHPV antibodies is less known [76] and studies with reliable data on the HPV antibody stability among children of different age groups are missing.

It has been discussed whether the development of HPV antibodies (and more generally an HPV infection) in early childhood protects from HPV infection or HPV associated diseases in later life $[62,77,78]$. Naturally acquired HPV antibodies provide protection against subsequent cervical HPV infections [79]. However, the effect of naturally acquired infections on immunity seems to be modest and type-specific, as the effect was only observed for HPV-16 infections [78, 79]. Rodriguez et al. [80] showed that type-specific HPV infections may reappear and may lead to precancerous lesions in previously exposed individuals, even though the risk was low. In addition, the magnitude of antibody response seems to influence immunity as shown in natural acquired compared to vaccination acquired antibody responses [62, 79, 81, 82]. The effect of naturally acquired HPV-16 antibodies seems to be also age-dependent and was lower in women $>25$ years compared to 15 - to 25-year-old women [62]. Focusing on seroprevalence in children and the potential influence of age, the question of naturally acquired immunity is even more relevant when investigating the most appropriate age for vaccination.

In Germany, HPV vaccination is recommended for girls by the Standing Committee on Vaccination (STIKO) since 2007 [83]. In 2018, the recommendation of a two doses HPV vaccine schedule (with an interval of at least 5 month) was extended to all boys and girls at ages 9-14 years [84]. HPV vaccination coverage in Germany is still low but coverage data indicates a steady increase of full (two dose) coverage among 15 year old girls from $27.2 \%$ in 2011 to $43.3 \%$ in 2018 [85]. Regarding HPV vaccination strategies, it is generally recommended that HPV vaccine should be given to children prior to sexual debut. On the basis of study results showing that children are already exposed to HR HPV types in young ages, it has been argued that prophylactic HPV vaccination could be more beneficial, if given at an earlier time point, e.g. at birth or in early childhood [16].

We observed no difference in HPV seropositivity in children regarding most of the demographic factors, like gender, or socioeconomic status. The significant higher prevalence ratio for HPV-16 seropositivity in the age groups $15-17$ years is in line with other publications and an expression of the sexual debut and the increase in sexual contacts. Slightly higher seroprevalence was found in West Germany compared to East Germany both for mucHPV 6, 11, 16 and 18, and for HPV-cut. The regional difference mirrors the old state border between the Federal Republic of Germany and the German Democratic Republic (1949 till 1990). Therefore, it is a potential factor of underlying socio-cultural differences between the two regions and described as a potential factor for prevalence differences of infectious diseases before [86].

There are a few conflicting studies about a potential association between obesity, measured mostly as body mass index, and HPV infections [87-89]. In our data, body mass index was negatively associated with HPV-16 seroprevalence in the univariate model of our data but was not significant in the final model. Even though body mass index may potentially play a role as a psychosocial risk factor in HPV exposure based on its influence on sexual activity [90], our data underline that there is no biological plausibility of such an association as this would have been seen in younger ages as well. We did not find any association between number of household members or number of siblings and HPV-16, 
HPV-18, or HPV-cut seropositivity, which could pose as an additional potential risk factor for horizontal HPV transmission [20, 28, 59, 91, 92]. A slightly higher seroprevalence with increasing numbers of siblings or household members was only found for low risk HPV types 6 and 11 in the fully adjusted models, which could be an indicator for hetero-inoculation due to horizontal transmission of HPV through genital warts, lesions in the oral cavity or laryngeal lesions among household members/siblings [3].

We observed a pronounced association of cutHPV seroprevalence with age. This result is in line with other studies, showing a strong increase of cutHPV in early years of childhood [13, 93]. There were no gender differences regarding cutaneous types, which was also expected as prevalence of skin warts is also not genderspecific $[93,94]$. An association between ultraviolet radiation exposure and cutaneous HPV infection (mainly of the beta genus) was described in other studies as it may play a role in the development of basal cell carcinoma and squamous cell carcinoma of the skin [95-97]. However, we did not observe any statistical association between number of experienced sunburns and seropositivity of any cutHPV in our data.

Due to the wide range of different mucosal and cutaneous HPV types included in the assay, the determination of seroprevalence largely depends on the applied cutoff value. There is a variety of serological HPV antibody detection methods, a lack of a universal applicable reference, and no standard cutoff values for type-specific HPV serology. Therefore, serological HPV studies often use a most likely negative cohort as the negative reference to calculate cutoff values. This, however, assumes negativity in this cohort and is challenging if the 'true' status is unknown. Our data was based on previous used cutoffs, established in a cohort of South Korean young women who claimed to have never had sexual contacts before and used for other studies with the same serological assay before [41, 44]. However, the challenges of HPV serology methods implicates a limitation in the comparison and explanatory power of seroprevalence differences between studies using different methods. Despite this limitation, the huge sample size of our study allows to compare seroprevalence of different age groups among the children, as they were all tested with the same methods.

Another potential limitation is antibody cross-reactivity for phylogenetically closely related HPV types, which could lead to an overestimation of seroprevalence for some types (e.g., HPV-16 and -33). However, there is no substantial cross-reactivity across phylogenetic species (e.g., alpha 7 and alpha 9, i.e., HPV-16 and -18) or genera, so the majority of our results are expected to reflect typespecific results.

\section{Conclusion}

To our knowledge, this is the first study on HPV antibody seroprevalence of cutaneous and mucosal HPV types among a large, representative sample of children and adolescents aged 1-17 years living in Germany. As a result of our study, we found varying age distributions in seroprevalence, dependent on type and tropism and we found low but non-zero seroprevalence for most tested mucHPV among children and adolescents. For HPV-16, only age and regional differences were associated factors with seropositivity. Compared to mucHPV, seroprevalence of cutHPV were higher and generally increased with age. Our study results provide population-based HPV seroprevalence data among children and adolescents and are an important data source of prior cumulative exposure to HPV in different age groups. Our data can serve as additional baseline data to understand the nature of HPV infections among children and adolescents and help evaluating the impact of the HPV vaccine introduction.

\begin{abstract}
Abbreviations
Cl: Confidence interval; cutHPV: Cutaneous HPV types; DKFZ: German Cancer Research Center; GNHIES98: German National Health Interview and Examination Survey 1998; HPV: Human papillomavirus; HPV-LR: Selection of low risk HPV types tested in our study: 6,11 ; HPV-HR: Selection of high risk HPV types tested in our study: $16,18,31,33,45,52,58$; HPV-cut: Selection of cutaneous HPV types tested in our study: 1, 4, 8, 10,38, 41,49; HPV-2val: HPV types in the bivalent vaccine: 16,18 ; HPV-4val: HPV types in the quadrivalent vaccine: 6,11 , 16, 18; HPV-9val: HPV types in the nonavalent vaccine: 6, 11, 16, 18, 31, 33, 45, 52, 58; KiGGS: German Health Survey for Children and Adolescents; mucHPV: Mucoseal HPV types; RKI: Robert Koch-Institute; PR: Prevalence ratios.
\end{abstract}

\section{Supplementary Information}

The online version contains supplementary material available at https://doi. org/10.1186/s12879-022-07028-8.

Additional file 1: Figure S1. Selection criteria of HPV types.

Additional file 2: Figure S2. Percentile plot of the antibody reaction (MFI values) of muscosal HPV types HPV-6, HPV-11, HPV-16, HPV-18, HPV31, HPV33, HPV45, HPV52, HPV58, HPV seroprevalence study $(n=12,257$, sera collected 2003-2006).

Additional file 3: Figure S3. Percentile plot of the antibody reaction (MFI values) of cutaneous HPV types HPV1, HPV4, HPV8, HPV10, HPV38, HPV41, HPV49, HPV seroprevalence study ( $n=12,257$, sera collected 2003-2006).

Additional file 4: Figure S4. Multiple HPV seropositivity by age, HPV seroprevalence study $(n=12,257$, sera collected 2003-2006).

Additional file 5: Table S1. Seroprevalence of individual mucosal human papillomavirus types by gender and age, HPV seroprevalence study $(n=12,257$, sera collected 2003-2006).

Additional file 6: Table S2. Seroprevalence of individual cutaneous human papillomavirus types by gender and age, HPV seroprevalence study ( $n=12,257$, sera collected 2003-2006).

Additional file 7: Table S3. Regression estimates for associated factors with seropositivity for HPV-6, HPV seroprevalence study $(n=12,257$, sera collected 2003-2006). 
Additional file 8: Table S4. Regression estimates for associated factors with seropositivity for HPV-11, HPV seroprevalence study $(n=12,257$, sera collected 2003-2006).

Additional file 9: Table S5. Regression estimates for associated factors with seropositivity for HPV-18, HPV seroprevalence study $(n=12,257$, sera collected 2003-2006).

\section{Acknowledgements}

We would especially like to thank all study participants and their parents who were and still are part in the German Health Interview and Examination Survey for Children and Adolescents (KiGGS). The authors wish to acknowledge the work of all colleagues at Robert Koch Institute who were involved in the development and implementation of the KiGGS cohort. We would also like to acknowledge the work of the laboratory staff involved in preparation and performing HPV serology at the German Cancer Research Center (DKFZ) in Heidelberg/Germany.

\section{Authors' contributions}

AL: analysis and interpretation of data; drafting of the manuscript; statistical analysis; critical revision of the manuscript. MP, TW: study concept and design; laboratory analysis; analysis and interpretation of data; revision of the manuscript. CP-M, TH, OW, MW-P.: study concept and design; analysis and interpretation of data; revision of the manuscript; study concept and design; analysis and interpretation of data. MT, RL, YD: critical revision of the manuscript. All authors read and approved the final manuscript.

\section{Funding}

Open Access funding enabled and organized by Projekt DEAL. This work was supported by the German Federal Ministry of Health and by in-house funding of the German Cancer Research Center (DKFZ) in Heidelberg/Germany. The funding source had no involvement in the study design and the preparation, review or approval of the manuscript.

\section{Availability of data and materials}

Data cannot be shared publicly because of confidentiality and personal data security restrictions. All data from the "German Health Interview and Examination Survey for Children and Adolescents (KiGGS)" are stored at the national public health institute Robert Koch-Institute. However, data are available upon request from the institutional data access for the scientific community as public use files: https://www.rki.de/EN/Content/Health_Monitoring/Healt hSurveys/HealthSurveys_node.

\section{Declarations}

\section{Ethics approval and consent to participate}

The "German Health Interview and Examination Survey for Children and Adolescents (KiGGS)" was approved by the Charité University Medicine Berlin ethics committee and the Federal Commissioner for Data Protection. Informed written consent and agreement were obtained from the parents of all participants.

\section{Consent of publication}

Not applicable.

\section{Competing interests}

AL, MP, TH, CP-M, MT, RL, YD, OW, MW-P declared that they have no conflict of interest. TW serves on advisory boards for MSD (Merck) Sharp \& Dohme.

\section{Author details}

${ }^{1}$ Department for Infectious Disease Epidemiology, Immunization Unit, Robert Koch-Institute, Berlin, Germany. ${ }^{2}$ Charité - Universitätsmedizin Berlin, corporate member of Freie Universität Berlin and Humboldt- Universität zu Berlin, Berlin, Germany. ${ }^{3}$ Infections and Cancer Epidemiology, German Cancer Research Center (DKFZ), Heidelberg, Germany. ${ }^{4}$ Department of Epidemiology and Health Monitoring, Robert Koch-Institute, Berlin, Germany. ${ }^{5} \mathrm{GP}$ Practice, Berlin, Germany. Institute of Hygiene and Environmental Medicine, Charité - Universitätsmedizin Berlin, corporate member of Freie Universität Berlin and Humboldt- Universität zu Berlin, Berlin, Germany.
Received: 8 July 2021 Accepted: 28 December 2021

Published online: 10 January 2022

\section{References}

1. Van Doorslaer K, Li Z, Xirasagar S, Maes P, Kaminsky D, Liou D, Sun Q, Kaur R, Huyen Y, McBride AA. The papillomavirus episteme: a major update to the papillomavirus sequence database. Nucleic Acids Res. 2017:45(D1):D499-506.

2. Lee B, Lee SW, Kim DI, Kim JH. HPV prevalence in the foreskins of asymptomatic healthy infants and children: systematic review and meta-analysis. Sci Rep. 2017;7(1):7050.

3. Syrjanen S. Current concepts on human papillomavirus infections in children. APMIS. 2010;118(6-7):494-509.

4. de Villiers EM, Fauquet C, Broker TR, Bernard HU, zur Hausen H. Classification of papillomaviruses. Virology. 2004;324(1):17-27.

5. Schiffman M, Castle PE, Jeronimo J, Rodriguez AC, Wacholder S. Human papillomavirus and cervical cancer. Lancet. 2007;370(9590):890-907.

6. International Agency on Research on Cancer (IARC). Human papillomaviruses. In: IARC monograohs on the evaluation of carcinogenic risks to humans, vol. 100B. Lyon: International Agency on Research on Cancer; 2012. p. 255-313.

7. Franco EL, Villa LL, Sobrinho JP, Prado JM, Rousseau MC, Desy M, Rohan TE. Epidemiology of acquisition and clearance of cervical human papillomavirus infection in women from a high-risk area for cervical cancer. J Infect Dis. 1999;180(5):1415-23.

8. Giuliano AR, Harris R, Sedjo RL, Baldwin S, Roe D, Papenfuss MR, Abrahamsen $\mathrm{M}$, Inserra P, Olvera S, Hatch K. Incidence, prevalence, and clearance of type-specific human papillomavirus infections: the young women's health study. J Infect Dis. 2002;186(4):462-9.

9. Giuliano AR, Lee JH, Fulp W, Villa LL, Lazcano E, Papenfuss MR, Abrahamsen M, Salmeron J, Anic GM, Rollison DE, et al. Incidence and clearance of genital human papillomavirus infection in men (HIM): a cohort study. Lancet. 2011:377(9769):932-40.

10. Antonsson A, Forslund O, Ekberg H, Sterner G, Hansson BG. The ubiquity and impressive genomic diversity of human skin papillomaviruses suggest a commensalic nature of these viruses. J Virol. 2000;74(24):11636-41.

11. Hufbauer M, Akgül B. Molecular mechanisms of human papillomavirus induced skin carcinogenesis. Viruses. 2017;9(7):187.

12. de Koning MN, Quint KD, Bruggink SC, Gussekloo J, Bouwes Bavinck JN, Feltkamp MC, Quint WG, Eekhof JA. High prevalence of cutaneous warts in elementary school children and the ubiquitous presence of wartassociated human papillomavirus on clinically normal skin. Br J Dermatol. 2015;172(1):196-201.

13. Antonsson A, Karanfilovska S, Lindqvist PG, Hansson BG. General acquisition of human papillomavirus infections of skin occurs in early infancy. J Clin Microbiol. 2003;41(6):2509-14.

14. Costa-Silva M, Fernandes I, Rodrigues AG, Lisboa C. Anogenital warts in pediatric population. An Bras Dermatol. 2017;92(5):675-81.

15. Silverberg MJ, Thorsen P, Lindeberg H, Grant LA, Shah KV. Condyloma in pregnancy is strongly predictive of juvenile-onset recurrent respiratory papillomatosis. Obstet Gynecol. 2003;101(4):645-52.

16. Cason J, Mant CA. High-risk mucosal human papillomavirus infections during infancy \& childhood. J Clin Virol. 2005;32(Suppl 1):S52-58.

17. Hajek EF. Contribution to the etiology of laryngeal papilloma in children. $J$ Laryngol Otol. 1956;70(3):166-8.

18. Mammas IN, Sourvinos G, Spandidos DA. The paediatric story of human papillomavirus (Review). Oncol Lett. 2014;8(2):502-6.

19. Pfister $\mathrm{H}$, zur Hausen H. Seroepidemiological studies of human papilloma virus (HPV-1) infections. Int J Cancer. 1978;21 (2):161-5.

20. Castellsague X, Drudis T, Canadas MP, Gonce A, Ros R, Perez JM, Quintana MJ, Munoz J, Albero G, de Sanjose S, et al. Human papillomavirus (HPV) infection in pregnant women and mother-to-child transmission of genital HPV genotypes: a prospective study in Spain. BMC Infect Dis. 2009;9:74.

21. Trottier H, Mayrand MH, Coutlee F, Monnier P, Laporte L, Niyibizi J, Carceller AM, Fraser WD, Brassard P, Lacroix J, et al. Human papillomavirus (HPV) perinatal transmission and risk of HPV persistence among children: design, methods and preliminary results of the HERITAGE study. Papillomavirus Res. 2016;2:145-52. 
22. Lee SM, Park JS, Norwitz ER, Koo JN, Oh IH, Park JW, Kim SM, Kim YH, Park C-W, Song YS. Risk of vertical transmission of human papillomavirus throughout pregnancy: a prospective study. PLoS ONE. 2013;8(6):e66368-e66368.

23. Rintala MA, Grenman SE, Puranen MH, Isolauri E, Ekblad U, Kero PO, Syrjanen SM. Transmission of high-risk human papillomavirus (HPV) between parents and infant: a prospective study of HPV in families in Finland. J Clin Microbiol. 2005;43(1):376-81.

24. Cason J, Kaye JN, Jewers RJ, Kambo PK, Bible JM, Kell B, Shergill B, Pakarian F, Raju KS, Best JM. Perinatal infection and persistence of human papillomavirus types 16 and 18 in infants. J Med Virol. 1995;47(3):209-18.

25. Doerfler D, Bernhaus A, Kottmel A, Sam C, Koelle D, Joura EA. Human papilloma virus infection prior to coitarche. Am J Obstet Gynecol. 2009;200(5):487.e481.

26. Sabeena S, Bhat P, Kamath V, Arunkumar G. Possible non-sexual modes of transmission of human papilloma virus. J Obstet Gynaecol Res. 2017:43(3):429-35.

27. Sinclair KA, Woods CR, Kirse DJ, Sinal SH. Anogenital and respiratory tract human papillomavirus infections among children: age, gender, and potential transmission through sexual abuse. Pediatrics. 2005;116(4):815-25.

28. Liu Z, Rashid T, Nyitray AG. Penises not required: a systematic review of the potential for human papillomavirus horizontal transmission that is non-sexual or does not include penile penetration. Sex Health. 2016;13(1):10-21.

29. Abreu AL, Souza RP, Gimenes F, Consolaro ME. A review of methods for detect human papillomavirus infection. Virol J. 2012;9:262.

30. Robbins HA, Li Y, Porras C, Pawlita M, Ghosh A, Rodriguez AC, Schiffman M, Wacholder S, Kemp TJ, Gonzalez P, et al. Glutathione S-transferase L1 multiplex serology as a measure of cumulative infection with human papillomavirus. BMC Infect Dis. 2014;14:120.

31. Tiggelaar SM, Lin MJ, Viscidi RP, Ji J, Smith JS. Age-specific human papillomavirus antibody and deoxyribonucleic acid prevalence: a global review. J Adolesc Health. 2012;50(2):110-31.

32. af Geijersstam V, Eklund C, Wang Z, Sapp M, Schiller JT, Dillner J, Dillner L. A survey of seroprevalence of human papillomavirus types 16, 18 and 33 among children. Int J Cancer. 1999;80(4):489-93.

33. Scherpenisse M, Mollers M, Schepp RM, Boot HJ, Meijer CJ, Berbers GA, van der Klis FR, de Melker HE. Changes in antibody seroprevalence of seven high-risk HPV types between nationwide surveillance studies from 1995-96 and 2006-07 in The Netherlands. PLoS ONE. 2012;7(11): e48807.

34. Marais D, Rose RC, Williamson AL. Age distribution of antibodies to human papillomavirus in children, women with cervical intraepithelial neoplasia and blood donors from South Africa. J Med Virol. 1997;51(2):126-31.

35. Kurth BM, Bergmann KE, Holling H, Kahl H, Kamtsiuris P, Thefeld W. The national child and adolescent health survey. The complete concept. Gesundheitswesen (Bundesverband der Arzte des Offentlichen Gesundheitsdienstes (Germany)). 2002;64(Suppl 1):S3-11.

36. Kamtsiuris P, Lange M, Schaffrath Rosario A. The German health interview and examination survey for children and adolescents (KiGGS): sample design, response and nonresponse analysis. Bundesgesundheitsblatt Gesundheitsforschung Gesundheitsschutz. 2007:50(5-6):547-56.

37. Kurth BM, Kamtsiuris P, Holling H, Schlaud M, Dolle R, Ellert U, Kahl H, Knopf $\mathrm{H}$, Lange M, Mensink GB, et al. The challenge of comprehensively mapping children's health in a nation-wide health survey: design of the German KiGGS-study. BMC Public Health. 2008;8:196.

38. Lange M, Kamtsiuris $P$, Lange $C$, Schaffrath Rosario A, Stolzenberg $H$, Lampert T. Sociodemographic characteristics in the German health interview and examination survey for children and adolescents (KiGGS) operationalisation and public health significance, taking as an example the assessment of general state of health. Bundesgesundheitsblatt Gesundheitsforschung Gesundheitsschutz. 2007;50(5-6):578-89.

39. Waterboer T, Sehr P, Michael KM, Franceschi S, Nieland JD, Joos TO, Templin MF, Pawlita M. Multiplex human papillomavirus serology based on in situ-purified glutathione s-transferase fusion proteins. Clin Chem. 2005;51(10):1845-53.

40. Clifford GM, Shin HR, Oh JK, Waterboer T, Ju YH, Vaccarella S, Quint W, Pawlita M, Franceschi S. Serologic response to oncogenic human papillomavirus types in male and female university students in Busan, South Korea. Cancer Epidemiol Biomark Prevent. 2007;16(9):1874-9.
41. Michael KM, Waterboer T, Sehr P, Rother A, Reidel U, Boeing H, Bravo IG, Schlehofer J, Gartner BC, Pawlita M. Seroprevalence of 34 human papillomavirus types in the German general population. PLoS Pathog. 2008;4(6): e1000091.

42. Espelt A, Mari-Dell'Olmo M, Penelo E, Bosque-Prous M. Applied prevalence ratio estimation with different regression models: an example from a cross-national study on substance use research. Adicciones. 2016;29(2):105-12.

43. Newall AT, Brotherton JM, Quinn HE, McIntyre PB, Backhouse J, Gilbert L, Esser MT, Erick J, Bryan J, Formica N, et al. Population seroprevalence of human papillomavirus types $6,11,16$, and 18 in men, women, and children in Australia. Clin Infect Dis. 2008;46(11):1647-55.

44. Scherpenisse M, Mollers M, Schepp RM, Boot HJ, de Melker HE, Meijer CJ, Berbers GA, van der Klis FR. Seroprevalence of seven high-risk HPV types in The Netherlands. Vaccine. 2012;30(47):6686-93.

45. Kramer M, Mollema L, Smits G, Boot H, de Melker H, van der Klis F. Agespecific HPV seroprevalence among young females in The Netherlands. Sex Transm Infect. 2010;86(7):494-9.

46. Heiligenberg M, Michael KM, Kramer MA, Pawlita M, Prins M, Coutinho RA, Dukers-Muijrers NH, Waterboer T. Seroprevalence and determinants of eight high-risk human papillomavirus types in homosexual men, heterosexual men, and women: a population-based study in Amsterdam. Sex Transm Dis. 2010;37(11):672-80.

47. Lupi S, Bergamini M, Guidi E, Gregorio P. Cross-sectional seroprevalence of antibodies against 6, 11, 16 and 18 human papilloma virus (HPV) types among teenagers and young women in Italy. Annali dell'Istituto superiore di sanita. 2014;50(2):171-7.

48. Joura EA, Kjaer SK, Wheeler CM, Sigurdsson K, Iversen OE, HernandezAvila M, Perez G, Brown DR, Koutsky LA, Tay EH, et al. HPV antibody levels and clinical efficacy following administration of a prophylactic quadrivalent HPV vaccine. Vaccine. 2008:26(52):6844-51.

49. Hamsikova E, Ludvikova V, Stasikova J, Tachezy R. Cross-sectional study on the prevalence of HPV antibodies in the general population of the Czech Republic. Sex Transm Infect. 2013;89(2):133-7.

50. Cubie HA, Plumstead M, Zhang W, de Jesus O, Duncan LA, Stanley MA. Presence of antibodies to human papillomavirus virus-like particles (VLPs) in 11-13-year-old schoolgirls. J Med Virol. 1998;56(3):210-6.

51. Mund K, Han C, Daum R, Helfrich S, Muller M, Fisher SG, Schiller JT, Gissmann L. Detection of human papillomavirus type 16 DNA and of antibodies to human papillomavirus type 16 proteins in children. Intervirology. 1997;40(4):232-7.

52. Hamsikova E, Ludvikova V, Smahel M, Sapp M, Vonka V. Prevalence of antibodies to human papillomaviruses in the general population of the Czech Republic. Int J Cancer. 1998;77(5):689-94.

53. Manns A, Strickler HD, Wikktor SZ, Pate EJ, Gray R, Waters D. Low incidence of human papillomavirus type 16 antibody seroconversion in young children. Pediatr Infect Dis J. 1999;18(9):833-5.

54. Chen CJ, Viscidi RP, Chuang CH, Huang YC, Chiu CH, Lin TY. Seroprevalence of human papillomavirus types 16 and 18 in the general population in Taiwan: implication for optimal age of human papillomavirus vaccination. J Clin Virol. 2007;38(2):126-30.

55. Dunne EF, Karem KL, Sternberg MR, Stone KM, Unger ER, Reeves WC, Markowitz LE. Seroprevalence of human papillomavirus type 16 in children. J Infect Dis. 2005;191(11):1817-9.

56. Vos RA, Pasmans H, Tymchenko L, Janga-Jansen AVA, Baboe-Kalpoe S, Hulshof K, de Melker HE, van der Klis FRM. High seroprevalence of multiple high-risk human papillomavirus types among the general population of Bonaire, St. Eustatius and Saba, Caribbean Netherlands. Vaccine. 2020;38(13):2816-26.

57. Jit M, Vyse A, Borrow R, Pebody R, Soldan K, Miller E. Prevalence of human papillomavirus antibodies in young female subjects in England. Br J Cancer. 2007;97(7):989-91.

58. Lehtinen M, Kaasila M, Pasanen K, Patama T, Palmroth J, Laukkanen P, Pukkala E, Koskela P. Seroprevalence atlas of infections with oncogenic and non-oncogenic human papillomaviruses in Finland in the 1980s and 1990s. Int J Cancer. 2006;1 19(11):2612-9.

59. Syrjanen S, Puranen M. Human papillomavirus infections in children: the potential role of maternal transmission. Crit Rev Oral Biol Med. 2000;11(2):259-74. 
60. Kaye JN, Starkey WG, Kell B, Biswas C, Raju KS, Best JM, Cason J. Human papillomavirus type 16 in infants: use of DNA sequence analyses to determine the source of infection. J Gen Virol. 1996;77(6):1139-43.

61. Rintala MA, Grenman SE, Jarvenkyla ME, Syrjanen KJ, Syrjanen SM. High-risk types of human papillomavirus (HPV) DNA in oral and genital mucosa of infants during their first 3 years of life: experience from the Finnish HPV family study. Clin Infect Dis. 2005;41(12):1728-33.

62. Castellsague X, Naud P, Chow SN, Wheeler CM, Germar MJ, Lehtinen M, Paavonen J, Jaisamrarn U, Garland SM, Salmeron J, et al. Risk of newly detected infections and cervical abnormalities in women seropositive for naturally acquired human papillomavirus type 16/18 antibodies: analysis of the control arm of PATRICIA. J Infect Dis. 2014;210(4):517-34.

63. Syrjänen S. Oral manifestations of human papillomavirus infections. Eur J Oral Sci. 2018;126(Suppl 1):49-66.

64. Rice PS, Cason J, Best JM, Banatvala JE. High risk genital papillomavirus infections are spread vertically. Rev Med Virol. 1999;9(1):15-21.

65. Sonnex C, Strauss S, Gray JJ. Detection of human papillomavirus DNA on the fingers of patients with genital warts. Sex Transm Infect. 1999;75(5):317-9.

66. Rice PS, Mant C, Cason J, Bible JM, Muir P, Kell B, Best JM. High prevalence of human papillomavirus type 16 infection among children. J Med Virol. 2000;61(1):70-5

67. Marais DJ, Sampson C, Jeftha A, Dhaya D, Passmore JA, Denny L, Rybicki EP, Van Der Walt E, Stephen LX, Williamson AL. More men than women make mucosal lgA antibodies to human papillomavirus type 16 (HPV-16) and HPV-18: a study of oral HPV and oral HPV antibodies in a normal healthy population. BMC Infect Dis. 2006;6:95.

68. Heim K, Hudelist G, Geier A, Szedenik H, Christensen ND, Concin N, Bergant A, Volgger B, Czerwenka K, Hopfl R. Type-specific antiviral antibodies to genital human papillomavirus types in mothers and newborns. Reprod Sci. 2007;14(8):806-14.

69. Marais D, Rose RC, Lane C, Aspinall S, Bos P, Williamson AL. Seroresponses to virus-like particles of human papillomavirus types 16, 18, 31, 33, and 45 in San people of Southern Africa. J Med Virol. 2000;60(3):331-6.

70. Pacheco-Dominguez RL, Durazo-Arvizu RA, Lopez-Hernandez A, FigueroaPadilla J, Ramirez-Gonzalez JB, Lopez-Cervantes M. Seroprevalence of HPV serotypes 6, 11, 16 and 18 in unvaccinated children from Mexico City. Epidemiol Infect. 2019;147:e257.

71. Ryding J, French KM, Naucler P, Barnabas RV, Garnett GP, Dillner J. Seroepidemiology as basis for design of a human papillomavirus vaccination program. Vaccine. 2008;26(41):5263-8.

72. Syrjänen S, Rintala M, Sarkola M, Willberg J, Rautava J, Koskimaa H, Paaso A, Syrjänen K, Grénman S, Louvanto K. Oral human papillomavirus infection in children during the first 6 years of life, Finland. Emerg Infect Dis J. 2021;27(3):759.

73. Dillner J. The serological response to papillomaviruses. Semin Cancer Biol. 1999;9(6):423-30.

74. Carter JJ, Koutsky LA, Hughes JP, Lee SK, Kuypers J, Kiviat N, Galloway DA. Comparison of human papillomavirus types 16, 18, and 6 capsid antibody responses following incident infection. J Infect Dis. 2000;181(6):1911-9.

75. Stanley M. HPV_-immune response to infection and vaccination. Infect Agent Cancer. 2010;5:19.

76. Antonsson A, Green AC, Mallitt KA, O'Rourke PK, Pandeya N, Pawlita M, Waterboer T, Neale RE. Prevalence and stability of antibodies to 37 human papillomavirus types - a population-based longitudinal study. Virology. 2010:407(1):26-32.

77. Franceschi S, Baussano I. Naturally acquired immunity against human papillomavirus (HPV): why it matters in the HPV vaccine era. J Infect Dis. 2014;210(4):507-9.

78. Rosillon D, Baril L, Del Rosario-Raymundo MR, Wheeler CM, Skinner SR, Garland SM, Salmeron J, Lazcano-Ponce E, Vallejos CS, Stoney T, et al. Risk of newly detected infections and cervical abnormalities in adult women seropositive or seronegative for naturally acquired HPV-16/18 antibodies. Cancer Med. 2019;8(10):4938-53.

79. Beachler DC, Jenkins G, Safaeian M, Kreimer AR, Wentzensen N. Natural acquired immunity against subsequent genital human papillomavirus infection: a systematic review and meta-analysis. J Infect Dis 2016;213(9):1444-54.

80. Rodriguez AC, Schiffman M, Herrero R, Hildesheim A, Bratti C, Sherman ME, Solomon D, Guillen D, Alfaro M, Morales J, et al. Low risk of type-specific carcinogenic HPV re-appearance with subsequent cervical intraepithelial neoplasia grade 2/3. Int J Cancer. 2012;131(8):1874-81.
81. Safaeian M, Porras C, Pan Y, Kreimer A, Schiller JT, Gonzalez P, Lowy DR, Wacholder S, Schiffman M, Rodriguez AC, et al. Durable antibody responses following one dose of the bivalent human papillomavirus $L 1$ virus-like particle vaccine in the Costa Rica Vaccine Trial. Cancer Prev Res. 2013;6(11):1242-50

82. Mesher D, Stanford E, White J, Findlow J, Warrington R, Das S, Pebody R, Borrow R, Soldan K. HPV serology testing confirms high HPV immunisation coverage in England. PLoS ONE. 2016;11(3): e0150107.

83. Ständige Impfkommission (STIKO). Mitteilung der Ständigen Impfkommission (STIKO) am Robert Koch-Institut: Impfung gegen humane Papillomaviren (HPV) für Mädchen von 12 bis 17 Jahren - Empfehlung und Begründung. Epidemiol Bull. 2007;12:97-103.

84. AG HPV der Ständigen Impfkommission (STIKO). Wissenschaftliche Begründung für die Empfehlung der HPV-Impfung für Jungen im Alter von 9 bis 14 Jahren. In: Epidemiol Bull. 2018. p. 233-50.

85. RieckTFM, Wichmann O, Siedler A. Impfquoten von Kinderschutzimpfungen in Deutschland - aktuelle Ergebnisse aus der RKI-Impfsurveillance. Epidemiol Bull. 2020;32(33):9-27.

86. Lachmann R, Loenenbach A, Waterboer T, Brenner N, Pawlita M, Michel A, Thamm M, Poethko-Muller C, Wichmann O, Wiese-Posselt M. Cytomegalovirus (CMV) seroprevalence in the adult population of Germany. PLoS One. 2018;13(7): e0200267.

87. Nyitray AG, Peng F, Day RS, Carvalho Da Silva RJ, Baggio ML, Salmeron J, Quiterio M, Abrahamsen M, Lazcano-Ponce E, Villa LL, et al. The association between body mass index and anal canal human papillomavirus prevalence and persistence: the HIM study. Hum Vaccines Immunother. 2019;15(7-8):1911-9.

88. Jung US, Choi JS, Ko JH, Lee JH, Park SY, Park SH. Decreased prevalence of high-risk human papillomavirus infection is associated with obesity. Eur J Gynaecol Oncol. 2013;34(1):70-4.

89. Liu S-H, Rositch AF, Viscidi RP, Silver MI, Burke AE, Gravitt PE. Obesity and human papillomavirus infection in perimenopausal women. J Infect Dis. 2013:208(7):1071-80.

90. Kershaw TS, Arnold A, Lewis JB, Magriples U, Ickovics JR. The skinny on sexual risk: the effects of BMI on STI incidence and risk. AIDS Behav. 2011;15(7):1527-38.

91. Weissenborn SJ, De Koning MN, Wieland U, Quint WG, Pfister HJ. Intrafamilial transmission and family-specific spectra of cutaneous betapapillomaviruses. J Virol. 2009;83(2):811-6.

92. Bussen S, Sutterlin M, Schmidt U, Bussen D. Anogenital warts in childhood-always a marker for sexual abuse? Geburtshilfe Frauenheilkd. 2012;72(1):43-8

93. Tamer E, Ilhan MN, Polat M, Lenk N, Alli N. Prevalence of skin diseases among pediatric patients in Turkey. J Dermatol. 2008;35(7):413-8.

94. Williams HC, Pottier A, Strachan D. The descriptive epidemiology of warts in British schoolchildren. Br J Dermatol. 1993:128(5):504-11.

95. Hampras SS, Giuliano AR, Lin HY, Fisher KJ, Abrahamsen ME, Sirak BA, Iannacone MR, Gheit T, Tommasino M, Rollison DE. Natural history of cutaneous human papillomavirus (HPV) infection in men: the HIM study. PLoS One. 2014;9(9): e104843.

96. Sampogna F, Bavinck JN, Pawlita M, Abeni D, Harwood CA, Proby CM, Feltkamp MC, Euvrard S, Naldi L, Neale RE, et al. Factors associated with the seroprevalence of 26 cutaneous and two genital human papillomavirus types in organ transplant patients. J Gen Virol. 2012;93(Pt 1):165-74.

97. lannacone MR, Wang W, Stockwell HG, O'Rourke K, Giuliano AR, Sondak VK, Messina JL, Roetzheim RG, Cherpelis BS, Fenske NA, et al. Sunlight exposure and cutaneous human papillomavirus seroreactivity in basal cell and squamous cell carcinomas of the skin. J Infect Dis. 2012;206(3):399-406.

\section{Publisher's Note}

Springer Nature remains neutral with regard to jurisdictional claims in published maps and institutional affiliations. 